\title{
Palliative Care as Response to Suffering at End of Life
}

\author{
Daniela MoşoiU*
}

Persons suffering from chronic and life limiting illnesses often have unrelieved symptoms such as pain, depression, fatigue, and psychosocial and spiritual distress. In Romania they are frequently left in the care of their families with little support from the health care system. It seems a paradox that those who are the sickest persons in a country find little place in the health care system. This article presents palliative care as a solution to the suffering for these patients and their families by describing the concept, models of services, its beneficiaries and benefits and presenting the history of development of hospice and palliative care worldwide and in Romania.

Keywords: suffering, palliative care, beneficiaries, benefits, services, history, worldwide, Romania

\section{Suffering at End of Life}

\section{Suffering Is Experienced when the Wholeness of a Person Is Threatened}

For professionals working with patients in the final part of their life the most frequent model used to describe suffering is the concept of "total pain" described by Dame Cicely Saunders, the founder of the modern hospice movement ${ }^{1}$. According to this model the four domains of pain that, in their totality, constitute "total pain" are: physical pain (and other distressing physical symptoms); psychological or emotional pain (eg. anxiety related to progression of disease, change of body image-hair loss after chemotherapy); social pain (eg. fear of separation from family members); and spiritual pain.

If we look just at the physical suffering a study done in 2009 in Romania concerning the patients with advanced cancer in the community the numbers of symptoms they experienced was on average 12,8 symptoms for patients at end of life ${ }^{2}$. Unrelieved, these symptoms can put a high burden on both the patients and their family.

* Daniela Moşoiu, MD, Assoc. Prof., Medical Faculty, “Transylvania” University, Braşov and Hospice Casa Speranţei Braşov; Str. Nicolae Bălcescu nr. 56; e-mail: daniela.mosoiu@hospice.ro.

1 Cicely Saunders, Nigel Sykes (ed.), The management of terminal malignant disease,3rd edition, London 1993, p. 45.

2 Luminiţa Dumitrescu L, Marinela Van den Heuvel-Olaroiu, "Caracteristicile medicale, psihosociale si socio-demografice ale pacientilor înrolati într-un program de îngrijire paliativă la domiciliu în România” in: PALIATIA 2 (1/2009), p. 4-14, http://www.paliatia.eu/ arhivapdf/PALIATIA-Vol2-Nr1-Ian2009-ro.pdf, viewed on May 2014.

RES 6 (2/2014), p. 227-245

DOI: $10.2478 /$ ress-2014-0118 
Another widely used definition of suffering in the medical field is the one provided by Eric Cassel. He defines suffering as "the state of severe distress associated with events that threaten the intactness of the person... suffering is experienced by persons. Suffering occurs when an impending destruction of the person is perceived; it continues until the threat of disintegration has passed or until the integrity of the person can be restored in some other manner" Suffering affects persons in all their complexity, and "can occur in relation to any aspect of the person, whether it is in the realm of social roles, group identification, the relation with self, body, or family, or the relation with a transpersonal, transcendent source of meaning" 3 .

The two models offer a practical framework for professionals to address suffering by looking in patients' history and narratives for the four dimensions of suffering and also highlighting the importance, meaning that a patient is attaching to the symptom alongside the intensity of the symptom. For example a patient who has been treated for bone cancer and is experiencing mild pain again might experience great suffering because of the meaning attached to the pain as a potential recurrence of the disease.

There are many opportunities for personal growth and maturation when facing one's mortality in a terminal illness. One can learn, even when 'it's too late,' from the consequences of negative and destructive behaviors to appreciate the value of the life remaining. This can lead to conscious changes in lifestyle and in the Christian context to repentance. In their suffering, the terminally ill have an imperative to finally seek real meaning in their lives and especially in their experience of suffering. " "Suffering... can transform life and become, as an icon experienced, a window opening on heaven."

\section{What is Palliative Care}

Palliative Care Is a Holistic Approach to Relieving the Suffering of People with Chronic and Life Limiting Illnesses

The World Health Organisation (2002) states that 'Palliative care is an approach that improves the quality of life of patients and their families facing the problems associated with life-threatening illness, through the prevention and relief

3 Eric J. Cassel, "The nature of suffering and the goals of medicine" in: NEngl J Med 306 (1982), p. 639-45.

4 Daniel B. Hinshaw, Jane Carnahan-Hinshaw, "A Christian Ending To Our Life" in: St Vladimir's Theological Quarterly (1/2000), p. 61-82.

5 Sharon Burns quoted by Vigen Guroian in: Life's Living Toward Dying, Grand Rapids 1996, p. 87. 
of suffering by means of early identification and impeccable assessment and treatment of pain and other problems, physical, psychosocial and spiritual ${ }^{6}$.

Four key goals for palliative care are universally understood: to provide relief from pain and other physical symptoms, to provide psychosocial and spiritual care, to maximize the quality of life and to provide support to help the family during the patient's illness and their bereavement. These goals stem from the understanding that a serious, life threatening illness is threatening not just the body of the sick person but the person as a whole, in all its dimensions: physical, emotional, spiritual and social, and has major impact both on the patient and his/her family. This concept of holistic care and the patient and family centred care is a big challenge to the health care systems that are deeply rooted into the biomedical model of care and are heavily focused on cure and not care ${ }^{7}$.

As stated by the World Health Organization ${ }^{8}$ palliative care affirms life and regards dying as a normal process, intends neither to hasten nor postpone death, offers a support system to help patients live as actively as possible until death and for family members to cope during the patient's illness and in their own bereavement. These principles show a clear dissociation of palliative care from euthanasia as palliative care is focused on life: it seeks to maximise its quality and to offer comfort for patients and their families parallel with recognition that life and death are normal parts of human existence. Studies have shown that while palliative care is enhancing the quality of life it may also positively influence the course of illness and prolong survival'.

"For secular people, sudden death is good, accepted and desirable, because they will not suffer and they will not be tormented by illnesses and old age. For believing Christians, though, sudden death is bad, because they are not given the possibility to prepare better for their encounter with Christ and the heavenly Church. When someone visits a high-ranking official, he prepares accordingly. We should do the same with respect to our encounter with Christ... From a Christian viewpoint, the hour and moment of death requires an appropriate preparation, that is, Confession, Holy Communion, Holy Unction, prayer by family and friends, our own prayer...Modern med-

${ }^{6}$ Cecilia Sepúlveda et al., "Palliative Care: The World Health Organization's Global Perspective" in: Journal of Pain and Symptom Management 24 (2/ 2002), p. 91-96.

7 George L. Engel, “The Need for a New Medical Model: A Challenge for Biomedicine.” in: Science 196 (1977), p. 129-136.

8 World Health Organization. National cancer control programmes: policies and managerial guidelines, 2nd ed. Geneva: World Health Organization, 2002.

9 Jennifer S. Temel et al., "Early palliative care for patients with metastatic non-small-cell lung cancer." in: N Engl J Med. 363 (2010), p. 733-742. 
ical methods pose a dilemma: "Prolongation of life or obstruction of death?" With everything that is offered by medical science the question is: "is our life prolonged so that we repent and devote it to God or is death obstructed, which creates a lot of pain, physical and existential?" 10

\section{Who will benefit from Palliative Care}

\section{Palliative Care Has Moved Beyond Caring for Cancer Patients to Other Chronic Progressive Illnesses}

In the past, palliative care was provided to cancer patients, in whom radical treatment was no longer indicated. Current approaches deem that palliative care can be provided to any chronic progressive intractable illness. These changes resulted from the realization, that problems arising at the terminal stage of life can already be envisaged in the early stages of the disease. The most common characteristic of palliative care movements in different countries is that the majority started with hospice care regarding end of life care and developed toward palliative care services considering the need for care of incurable patients. Even in the developed world, when patients present earlier to the health care system and there is a greater chance that their disease is curable, a comprehensive approach to their care that integrates palliative care throughout their illness experience will provide them with better quality of life. ${ }^{11}$

Palliative care towards end of life has been offered mostly to cancer patients but can now be offered for a wider range of serious illnesses and integrated more broadly across health care services. ${ }^{12}$ The most common chronic illnesses are heart disease, cancer, AIDS, stroke, chronic respiratory disease, neurological disease or dementia.

Populations in European and other developed countries are ageing, and more people are now living with the effects of chronic illnesses towards the end of life. This means that there will be more people needing some form of help towards the end of life. ${ }^{13}$ With the rapidly aging world population and

\footnotetext{
10 Metropolitan Hierotheos of Nafpaktos, The Mystery and the Process of Death. An interview by Pavel Chirila, Professor and Doctor at St Irene's Hospice in Bucharest, http://ocl.org/themystery-and-the-process-of-death, viewed on February the $13^{\text {th }}, 2014$.

11 Irene J. Higginson et al., "Is there evidence that palliative care teams alter end-of-life experiences of patients and caregivers?" in: Journal of Pain and Symptom Management 25 (2003), p. 150-168.

12 World Health Organization Europe, The Solid facts Palliative Care, WHO regional Office Europe Copenhagen 2004, http://www.euro.who.int/_data/assets/pdf_file/0003/98418/ E82931.pdf, viewed on February the $15^{\text {th }} 2014$.

13 Vicki A. Freedman et al., "Recent trends in disability and functioning among older adults in the United States. A Systematic Review” in: JAMA 288 (24/2002), p, 3137-3146.
} 
the associated increase of multiple "non-communicable" diseases, the need for palliative care will increase dramatically over the next decades. As populations age, the pattern of diseases that people suffer and die from also changes. However, if more people live to older ages, and if chronic diseases become more common with age, then the number of people in a population living with their effects will increase. ${ }^{14}$ There are official guidelines to incorporate palliative care for seriously chronic progressive illnesses within aging policies and to promote better care towards the end of life ${ }^{15}$.

The population of young people with life-limiting conditions is growing as many chronic progressive conditions now reach a crisis during late adolescence and young adulthood. Children and young people accessing children's palliative care services will have a wide range of conditions including some cancers. The length of illness can vary greatly from days to years. The child may survive into early adulthood, extending palliative care over many years.$^{16}$

\section{What are the Benefits of Palliative Care}

\section{The Major Benefits of Palliative Care Include Better Pain Control and Less Depression Resulting in Much Improved Quality of Life for Patients and Their Caregivers}

As Temel study pointed out the patients who are having early palliative care have better quality of life and less than half of depressive symptoms in comparison with those who are receiving standard oncologic treatment ${ }^{17}$.

Palliative care and hospice teams identify and rapidly treat distressing symptoms that have been independently shown to increase medical complications and hospitalization insuring better control of pain, depression and other distressing symptoms. An analysis of 33 high quality systematic literature reviews and 89 intervention studies concluded that there is strong to moderate evidence that palliative care improves important aspects of end of life care, such as reduction in distressing symptoms and relief of caregiver burden ${ }^{18}$.

\footnotetext{
14 Joanne Lynn, David M. Adamson, Living well at the end of life: adapting health care to serious chronic illness in old age, Arlington, VA, Rand Health, 2003.

15 World Health Organization, Better Palliative Care for Older People. WHO regional Office for Europe 2004.

16 World Health Organization, Cancer Pain Relief and Palliative Care in Children, Geneva, Switzerland: World Health Organization, 1998.

17 J.S. Temel et al., "Early palliative care".

18 Karl A. Lorenz et al., reported in Rand Europe and the National Audit Office, 2008, The Potential Cost Savings of Greater Use of Home-and Hospice-Based End of Life Care in England, National Audit Office, 2008.
} 
PC services enhance quality of care also due to their measurable impact on reducing ICU and total bed days but also for their efficacy in supporting transitions from high- intensity, high-cost hospital settings to more appropriate and desired care settings, such as home. Studies of a range of palliative care interventions from Europe, Canada, Australia and the US demonstrate consistent improvement in pain and other symptoms, patient and family satisfaction, and likelihood of receiving care in the place of choice. ${ }^{19}$

Also hospital palliative care consultation programs have been associated with reductions in symptoms and higher family satisfaction with overall care, and greater emotional support as compared with usual care. ${ }^{20}$

Palliative Care Insures Better Quality of Life for Caregivers and Reduces the Risk for Developing Depressive Disorders.

The end of life (EOL) discussions may have cascading benefits for patients and their caregivers. Despite physicians' concerns that patients may suffer psychological harm due to EOL discussions, there is no evidence that they were significantly associated with increased emotional distress or psychiatric disorders. Instead, the worst outcomes were seen in patients who did not report EOL conversations. This group received significantly more aggressive medical care in their final week of life, which was associated with worse patient quality of life near death. In addition, their bereaved caregivers experienced worse quality of life, more regret, and were at higher risk for developing a Major Depressive Disorder. ${ }^{21}$

\section{Palliative Care Services Facilitate The Care of Patients in the Place that They Choose}

Palliative care services contribute to the continuity and coordination of care. Palliative care and hospice teams meet frequently with patients and their families to establish appropriate and realistic goals, support families in crisis, and plan for safe transitions out of hospitals to more supportive settings. Communication regarding the patient's prognosis and goals by a dedicated team with time and expertise leads to better-informed decision making, clarity of the care plan, and consistent follow-through. Such discussions at family

\footnotetext{
19 David Casarett et al., "Do Palliative Care Consultations Improve Patient Outcomes?" in: Journal of the American Geriatric Society 56 (2008), p. 593-599.

20 R. Sean Morrison et al., "Cost Savings Associated with US Hospital Palliative Care Consultation Programs” in: Archives of Internal Medicine 168 (16/2008), p. 1786.

${ }^{21}$ Baohui Zhang et al., "Health Care Costs in the Last Week of Palliative Care Life: Associations with End of Life Conversations" in: Archives of Internal Medicine 169, (5/2009) p. 480-488.
} 
meetings lead to lower costs and a lighter family burden and improve family satisfaction and bereavement outcomes.

Results of a randomized trial of in-home palliative care in two US health organizations found that patients reported greater satisfaction with care at 30 and 90 days after enrolment and were more likely to die at home, their preferred location, than those receiving usual care. They were also less likely to visit emergency departments or to be admitted to hospital than those receiving usual care. The study provided strong clinical and cost saving evidence supporting the provision of palliative care in the home of terminally ill patients with cancer, chronic heart failure and chronic obstructive lung disease with a life expectancy of approximately 1 year. ${ }^{22}$

\section{Early Integration of Palliative Care Prolong the Survival Time}

There is evidence of prolonged survival time for patients with heart failure, lung cancer pancreatic cancer and colon cancer. Although patients receiving early palliative care had less aggressive treatment at end of life but longer survival.

\section{Other Benefits of Palliative Care Include Avoiding Unnecessary Treatments and Reduced Costs}

There is extensive evidence that providing palliative care (in different settings) for patients who can benefit from it appears to significantly lower costs in multiple ways: by decreasing hospital days and a shift to outpatient care; with significantly fewer diagnostic services, treatments, tests and interventional procedures; by reducing the medication costs and reducing the aggressive medical care in the patient's final week of life. Hospital palliative care consultation teams are associated with significant hospital cost savings. This was the finding of a US study involving analysis of data from 8 hospitals with established palliative care programs. ${ }^{23}$

Unnecessary and unplanned treatments are avoided as palliative care helps patients avoid hospitalization, readmissions, and emergency department visits due to appropriate symptom management and good communication; patients are less likely to be admitted to ICU mainly because of discussions about the goals of care and the facilitation of patient and family decisions about the types and settings of future care.

\footnotetext{
22 Richard Brumley et al., "Increased Satisfaction with Care and Lower Costs: Results of a Randomized Trial of In-Home Palliative Care" in: Journal of the American Geriatric Society 55 (7/2007), p. 993-1000.

23 R. S. Morrison et al., "Cost Savings", p. 1783-1790.
} 
A US study found that patients with advanced cancer who reported having end of life discussions with their doctors had on average 35\% lower health costs (\$US1041) in the final week of life compared with similar advanced cancer patients who had not had those discussions. Higher costs among those advanced cancer patients who had not had end of life discussions with their doctors were associated with more physical distress in the last week of life and worse overall quality of death as reported by the caregiver. There was no survival difference associated with higher healthcare expenditures ${ }^{24}$. Similar data were generated by a study in Spain showing that the provision of palliative care services to advanced cancer patients generated savings of $61 \%$ in the cost of care during the last 6 weeks of life compared with conventional medical care ${ }^{25}$.

\section{Models of Palliative Care Service Deliveries}

\section{Palliative Care Comprises Several Services}

There are several types of palliative care services available worldwide, delivered in many forms and structures, depending on the available resources, the characteristics of the national health care services and the general economic background. The main types of services developed in European countries include the following ${ }^{26}$ :

Inpatient care provided in:

- Free-standing hospices or palliative care units are physically separate from the hospital, but should be able to access its staff and services. Patients may be admitted for symptom management (physical or psychosocial), terminal care, short duration rehabilitation/convalescence, to provide a period of respite for family carers. They have a warm environment of care and an interdisciplinary team (physician, nurse, social worker, priest, therapist, psychologist, cleric, volunteers) that offers 24/24 hour supervised care for patients in critical, advanced or terminal stages

24 B. Zhang, "Health Care Costs", p. 480-488.

25 Xavier Gomez-Batiste et al., "Resource Consumption and Costs of Palliative Care Services in Spain: A Multicentre Prospective Study" in: Journal of Pain and Symptom Management 31 (6/2006) , p. 522-532.

26 Recommendation Rec (2003) 24 of the Committee of Ministers to member states on the organisation of palliative care, http://www.coe.int/t/dg3/health/Source/Rec(2003)24_ en.pdf, viewed on February the $15^{\text {th }} 2014$. 
- Palliative care departments/wards in chronic or acute hospitals are units devoted to patients who require palliative care while receiving active therapy or for end-of-life care. According to the European Society for medical Oncology (ESMO), the Minimum Standards for the Provision of Supportive and Palliative Care require all cancer centres to provide patients with the needed palliative care or make adequate arrangements of such care with a hospice/palliative care unit

Mobile palliative care teams in acute hospitals are interdisciplinary palliative care teams in large hospitals, visiting patients with incurable illnesses admitted for acute conditions, at the request of the ward consultant. Mobile teams operate in general and specialist hospitals and are staffed by physicians and nurses trained and experienced in palliative care; some also have a social worker or a pastoral care specialist; They facilitate the provision of high quality palliative care in all wards where the patient is admitted, without the need to be transferred to another unit;

\section{Home-based Palliative Care}

There are various models for community based palliative care services, depending on the available resources and the degree of integration of palliative care into the mainstream of the health care system:

- Specialized services providing 'hands-on' care are the most appropriate if there are no other nursing or specialized services in the patients' homes. Care is provided by a core interdisciplinary team (palliative care physician, palliative care nurse, social worker and preferably other allied health services. Patients are evaluated by the palliative care physician and visited by team members as often as necessary for: pain and symptom control, psycho-emotional, spiritual and social support.

- Advisory services - they are appropriate when there is a good primary care centred around the GPs and the community nurses. The palliative care team (palliative care physician, community palliative care nurse, social worker, other allied health professionals, cleric and volunteers) has an advisory role for the GP who is prescribing the drugs.

- Comprehensive community palliative care services operate in very few developed countries and are able to provide all the specialized palliative care in the patents' homes, from confirming diagnosis, investigations, chemotherapy, physiotherapy, blood transfusions, family support etc. 
Home care is generally preferred by patients and families ${ }^{27}$, if adequate support is provided; it offers opportunities to cooperate with and involve family doctors and to support families during the patients' care and during bereavement.

Day centre care enables patients in stable condition with advanced disease to benefit from a multidisciplinary approach in a non-medical and friendly environment. They encourage socializing of patients with similar conditions, under the supervision of specialized nurses, and offer occasional medical consultations and nursing care, as well as other types of support (physiotherapy, occupational/art therapy, psycho-emotional and spiritual support).

Out-patient care. This is provided in specialized palliative care clinics usually attached to inpatient units, hospices or home-based services, and addresses the needs of patients in advanced but stable condition of their disease who do not yet need regular home care visits or admissions into in-patient units for palliative care.

Palliative care out-patient clinics are staffed by palliative care physicians and nurses and other allied health care professionals (psychologist, social worker). They encourage patients' independence as long as possible, offer specialized consultations and counselling, and familiarize them with the hospice/ palliative care staff and environment.

\section{History of Palliative Care World Wide}

\section{Modern Palliative Care Developed in the Late Twentieth Century}

Modern palliative care developed rapidly in western countries in the last part of the twentieth century in response to the increasing marginalisation of death in society and the medicalisation of dying within the healthcare system. It began to make progress in developing countries to address the problem of avoidable suffering at the end of life. Today it is increasingly recognised across the world as a medical speciality

Four health care developments during the middle of the $20^{\text {th }}$ century influenced the approach to caring for the dying: ${ }^{28}$

1. The professional literature about the dying started to shift from anecdote to systematic observation

27 Barbara Gomes et al., "Heterogeneity and changes in preferences for dying at home: a systematic review" in: BMC Palliative Care 2013, 12:7, http://www.biomedcentral. com/1472-684X/12/7, viewed on February the $15^{\text {th }} 2014$.

28 David Clark, "From margins to centre: a review of the history of palliative care in cancer" in: The Lancet Oncology 8 (5/2007), p. 430-438. 
2. A new view of dying began to emerge which sought to foster concepts of personal dignity, autonomy and meaning at the end of life

3. An active rather than passive approach to the care of the dying was promoted with increasing vigour

4. A growing understanding developed about the interdependence between mental and physical distress

During the early sixties Dame Cicely Saunders began to forge a modern philosophy of terminal care combining a powerful religious and moral conviction alongside a rigorous approach to observation, research and clinical innovation. Her vision for improving the care of the dying encompassed the physical, psychological, social and spiritual domains, whilst emphasising the importance of clinical practice, training and research. By listening to patients' stories of illness and suffering Saunders evolved the concept of 'total pain'. This view of pain moved beyond the physical to encompass the social, emotional and spiritual aspects of suffering. Her message was clear --- 'constant pain needs constant control. ${ }^{29}$

Saunders philosophy of caring for the dying focused on total patient care, family care, bereavement care and the need for true interdisciplinary teamwork. Her pioneering work revolutionised the way in which the varied needs of dying patients and their families were met. In a short period of time, she transformed the approach to caring for the dying and challenged many of the established negative attitudes and biases. In 1967 Saunders founded St Christopher's Hospice in South London. As the first 'modern' hospice it was unique in combining three key principles: excellent clinical care, education and research and it soon became an inspiration to others around the world.

Elsewhere in the world, others were also working to improve the experience of the dying and their families. In 1965 Glaser and Strauss published their research into the experiences of dying patients in hospitals in the US ${ }^{30}$. In 1969 Dr. Elisabeth Kübler Ross outlined her ideas on the stages of dying and how to communicate with patients who were dying. ${ }^{31}$ Canadian physician Balfour Mount adapted Saunders' model for Canada developing a hospital-based approach and creating a specialized palliative care ward at the Royal Victoria Hospital, Canada in 1975.

29 C. Saunders, "The management of patients in the terminal stage" in: Ronald W. Raven (ed.), Cancer, Vol. 6. London 1960, p. 403-417.

30 Barney G. Glaser, Anselm L. Strauss, Awareness of Dying, Chicago 1965.

31 Elisabeth Kübler Ross, On Death and Dying, London 1969. 
Over time, the focus of 'terminal care' widened from caring for those who were actively dying to those who experienced problems with symptom control earlier in their disease progression. This shift in focus led to helping dying patients live their remaining life to the full and prompted practitioners to question the term 'terminal care' to describe their work. The new term 'palliative care' was coined by Balfour Mount to describe the approach of caring for dying patients and their families, this term is now used world-wide. ${ }^{32}$

Since Its Beginning Palliative Care Has Become A Significant Part of Health Care Services in Several Countries

The World Wide Palliative Care Alliance characterizes global development of palliative care into 6 categories as follows ${ }^{33}$ :

- Level 1 No Known Activity

- Level 2 Capacity Building (countries where there is no palliative care service established but there is evidence of wide-ranging initiatives designed to create the capacity for hospice-palliative care services to develop)

- Level 3a Isolated Provision (the development of palliative care is patchy, often home-based in nature and not well-supported; limited availability of morphine).

- Level 3b Generalized Provision (the development of palliative care in a number of locations with the growth of local support in those areas, multiple sources of funding, availability of morphine, provision of some training and education initiatives)

- Level 4a Preliminary Integration (the development of a critical mass of palliative care in a number of locations', a variety of palliative care providers and types of services, availability of morphine and some other strong pain-relieving drugs, limited impact of palliative care on policy, provision of a substantial number of training and education initiatives by a range of organisations)

- Level 4b Advanced integration (the development of a critical mass of palliative care in a wide range of locations, comprehensive provision of all types of palliative care by multiple service providers, broad awareness of palliative care, unrestricted availability of morphine and all other strong pain-relieving drugs, substantial impact of palliative

\footnotetext{
32 "Mount B. The Royal Victoria Hospital Palliative Care Service: a Canadian experience" in: C. Saunders, R. Kastenbaum (eds.), Hospice care on the international scene, New York 1997.

33 Thomas Lynch et al., "Mapping Levels of Palliative Care Development; A Global Update" in: Journal of Pain and Symptom Management 45 (6/2013), p. 1094-1106.
} 
care on policy, in particular on public health policy, the development of recognised education centres, academic links forged with universities, the existence of a national palliative care association. Romania is classified on this level.

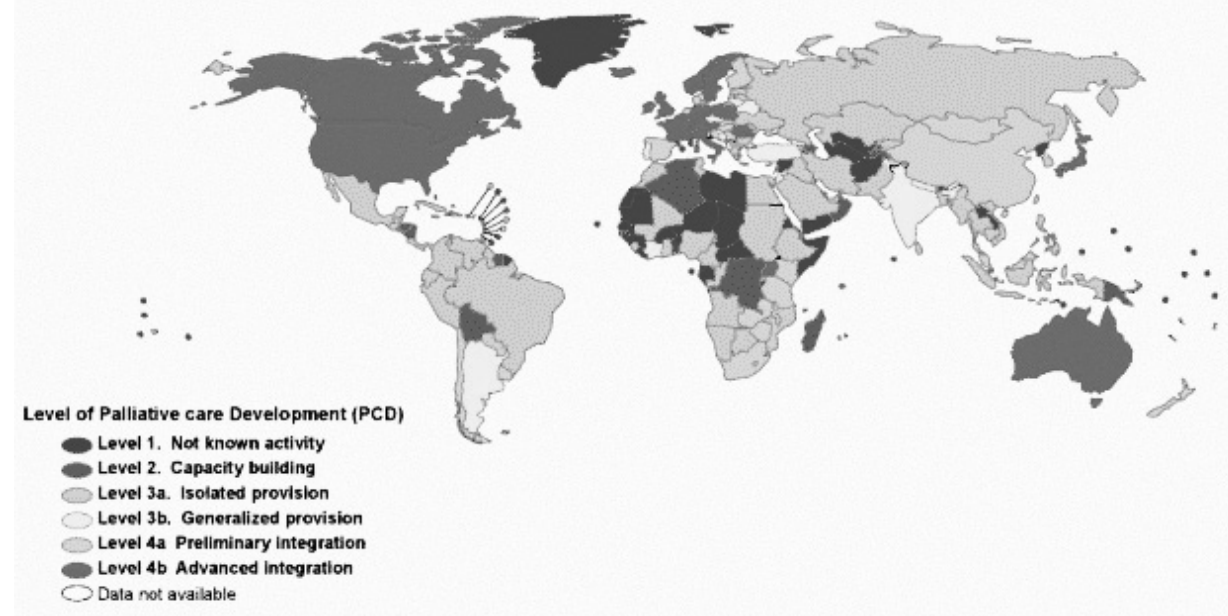

Reproduction with permission from Lynch \& collaborators

\section{Palliative Care in Romania}

Palliative Care in Romania Started in the Voluntary Sector and has Progressed into the Public Sector

Palliative care services developed slowly in Romania after the fall of communism. In the early 90's palliative care charitable organizations were set up with international financial and know-how support as a response to the urgent need for improved care for the patients with chronic and incurable diseases. NGOs were able to react to community needs more rapidly than the public system.

In 1989 over $50 \%$ of the HIV/AIDS children in Europe were in Romania. As result, several isolated hospices were set up in 1992 in Cernavoda, Bucuresti and Curtea de Arges.

The turning point of the palliative care movement in Romania came in 1992 with the charitably organized and sponsored Hospice Casa Speranţei 
(Brasov) initiative. It started as a palliative home care service for adults in advanced stages of cancer, after their discharge from the public oncology hospital. It was a initiative of the British philanthropist Graham Perolls, as a partnership between the Brasov hospice and a twin organization in the UK (Hospice Ellenor in Dartford, Kent). Over the last twenty years Hospice Casa Speranţei has played a pioneering role in developing various palliative care services in Romania, in coordinating national education programmes in palliative care, in working for legislative changes in support of the hospice/palliative movement and in advocating for its inclusion in the mainstream of the health care system.

Palliative care services have been set up in many counties as local initiatives, mostly funded from international charitable organizations or funding agencies. At the end of 2012 there were 57 palliative care service providers (19 public, 26 charitable, 12 for-profit) insuring a national coverage of 5,4\% of palliative care need. ${ }^{34}$ Most of these providers had one-type service (inpatient units, home-based care, outpatient clinics, day centres or mobile hospital teams). The distribution of service providers is uneven. The map of Romania below shows the distribution of functional palliative care services at the end of 2012.

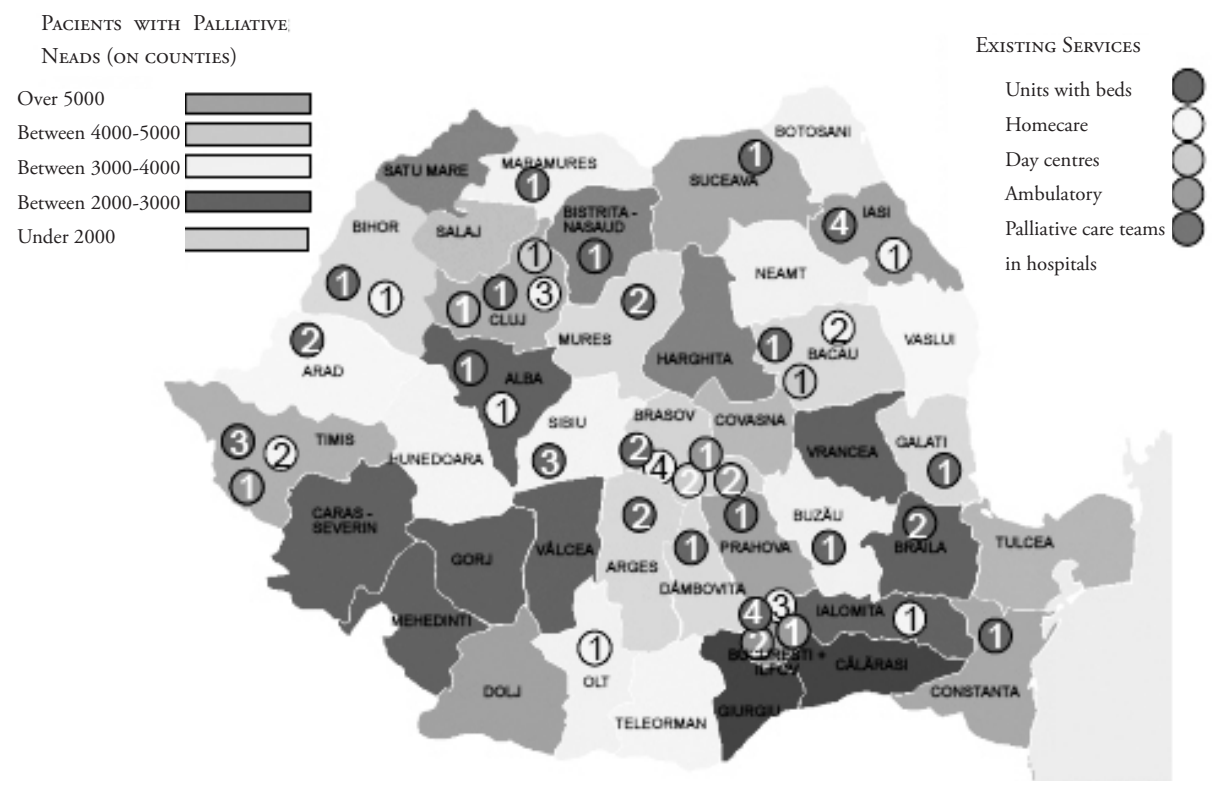

The Development of Palliative Care in Romania has Been Encouraged by Enabling Legislation

34 Catalogul furnizorilor de Ingrijiri palliative Brasov, Hospice Casa Sperantei 2012, http:// www.anip.ro/wp-content/uploads/2013/08/Catalog-servicii-ingrijiri-paliative-RO-2012. pdf, viewed on February the $16^{\text {th }} 2014$. 
Between 1992 and 2008 most palliative care initiatives in Romania were by the non-governmental sector. After 2005, several legislative changes in favour of palliative care development, as well as the new funding mechanisms adopted by the health insurance system for the reimbursement of inpatient care services, created incentives for public hospitals to set up palliative care wards or departments. These initiatives were erratic and are not yet part of the mainstream health care system network.

Examples of current legislation positively influencing palliative care development include:

National strategies and general laws: Law no.46/2003 of patient's right, stating that: "The patient has the right to terminal care, to die in dignity"; Law No.95/2006 of the health care reform in Romania includes palliative care among the services provided in primary care and hospitals; National strategy for the sustainable development of Romania - Horizons 2013-2020-2030, published in the Official gazette, part 1bis, No. 824bis of 8.12.2008 envisages: "Increase in coverage of basic services for the population such as emergency services, 50\% increase of access to health care services (long-term care) for the elderly, increase of coverage with palliative care services to 60\% [by 2020]".

Palliative care services: Inpatient palliative care included (since 2007) in the annual Frame-Contract of the National House of Health Insurances for the provision of health services in Romania; Home-based palliative care included (since 2010) in the annual Frame-Contract for the provision of health services in Romania; Various legal requirements for the authorization and accreditation of services, issued by the Ministry of Health and the national House of Health Insurance.

Human resources: Salaries of clinical staff working in difficult or dangerous environments (including palliative care) are entitled to up to $50 \%$ monthly bonus added to salary. Staffing ratio for palliative care inpatient units set by Health Ministry order No.1778/2010

Professional education: Palliative care education legalized as "subspecialty" and curricula accepted by OM No.916/1999 and No.480/2005; Palliative care included in the nursing college curricula by OMECT No.2713/2007

Medication: access to pain control medication improved by Law no.339/2005

Standards, protocols: National standards for palliative care (in inpatient units and home care) developed in 2002 with support from NHPCO (USA), and upgraded in 2009 (for inpatient units, home-based care and outpatient clinics); unofficially assumed by palliative care providers. Palliative 
care protocols developed and launched at the annual conference (2011) of the National Palliative Care Association

\section{Funding of services}

Since 2004 the House of Health Insurance covers home-based medical care packages of services. In 2009 the difference is accepted between general medical home care and palliative home care, and the funding mechanism of costs/visit replaces the cost/list of services reimbursement

Since 2007 the House of Health Insurance provides partial funding by cost/patient/day in palliative care inpatient units, initially based on costs tariffs negotiated between providers and local houses on insurances, and starting in 2010 by maximal tariffs at national level.

Currently the government is contemplating the possibility of developing palliative care nationally with funding from the World Bank.

\section{Hospice Casa Speranţei Braşov România Has Played a Role of Beacon Centre for Education of Professionals in Eastern Europe}

In a research done on palliative care services in Eastern Europe ${ }^{35}$ Hospice Casa Speranţei (HCS) was fulfilling the criteria for being a beacon for palliative care development and was named as one of the 5 centres of excellence in palliative care in Eastern Europe. This role has continued over the years through the active involvement in the support of development of services throughout Romania but also surrounding countries especially Moldova, advocacy for legal changes especially access to pain medication and inclusion of financial provisions for palliative care in the funding system

Hospice "Casa Speranţei” developed partnerships with other NGO's under the umbrella of the Coalition of palliative care providers but also public- private partnership with DGASP (General Direction for Social Assistance and Protection) for collaborating in care for institutionalized children with special needs and with the Health Ministry working for the national palliative care strategy. HCS is heading the palliative care commission in the Ministry of Health and running the 18 months national subspecialty course for doctors.

At present HCS offers services to around 2577 patients annually both in Brasov and Bucharest and in the rural area of Brasov County, has trained over 13000 professionals and is the process of opening a new hospice in Bucharest.

35 D. Clark, Michael Wright, Transition in End of Life Care, Buckingham 2003, p. 180-194. 


\section{Perception of Palliative Care in Romania}

Romanian Health Providers Make No Clear Distinction between Palliative Care and Terminal Care

A study was conducted by Hospice Casa Speranţei among 386 stakeholders (hospital managers, oncologists, cardiologists, neurologists, and oncology nurses) working in the public hospitals. The stakeholder interviewed were not necessarily trained in palliative care or working with a palliative care team. Their answers showed a diversity of understanding from a general perspective to a more particular approach (Table 1)

Table 1: Understanding of Romanian health care providers on Palliative Care

\begin{tabular}{|c|c|c|c|c|c|}
\hline \multicolumn{6}{|c|}{ What does Palliative Care means for you? (open ended question) } \\
\hline & $\begin{array}{l}\text { Oncologist } \\
\text { physician }\end{array}$ & $\begin{array}{l}\text { Oncology } \\
\text { nurse }\end{array}$ & $\begin{array}{l}\text { Cardiologist } \\
\text { physician }\end{array}$ & $\begin{array}{l}\text { Neurology } \\
\text { physician }\end{array}$ & $\begin{array}{l}\text { Hospital } \\
\text { managers }\end{array}$ \\
\hline $\begin{array}{l}\text { Care of patients } \\
\text { in terminal stages }\end{array}$ & 27 & 27 & 5 & 9 & 17 \\
\hline $\begin{array}{l}\text { Assistance and } \\
\text { treatment for } \\
\text { incurable patient }\end{array}$ & 10 & 2 & 2 & 2 & 11 \\
\hline $\begin{array}{l}\text { Total care for non } \\
\text { curative patients }\end{array}$ & 25 & 9 & 6 & 6 & 2 \\
\hline $\begin{array}{l}\text { Symptoms' } \\
\text { control }\end{array}$ & 23 & 8 & 8 & 6 & 1 \\
\hline $\begin{array}{l}\text { Ensure patient's } \\
\text { quality of life }\end{array}$ & 18 & 9 & 4 & 8 & 9 \\
\hline Pain relief & 10 & 2 & 2 & & 4 \\
\hline Holistic care & 7 & & 2 & & \\
\hline Suffering relief & 7 & 17 & 5 & 8 & \\
\hline $\begin{array}{l}\text { Others(not } \\
\text { mentioned) }\end{array}$ & 10 & 9 & 7 & 8 & 10 \\
\hline NA & 8 & 7 & 4 & 2 & 3 \\
\hline Total & 145 & 90 & 45 & 49 & 57 \\
\hline
\end{tabular}

The physicians described the most important groups of patients requiring palliative care as those: with pain (pain relief and other symptom control), 
who are seriously ill patients, where there is interruption of curative therapies and at the terminal stage of disease.

According to its definition, palliative care is applicable early in the course of illness, in conjunction with other therapies that are intended to prolong life, such as chemotherapy or radiation therapy, and includes those investigations needed to better understand and manage distressing clinical complications. This aspect of palliative care is not well understood by the health care professionals.

Public Perceptions of Palliative Care in Romania Identify the Need to Improve Service at the Primary Care Level

A national survey was conducted in 2007 to find out the Romanian citizens' level of information, attitudes and perception related to the needs of individuals with incurable conditions. ${ }^{36}$

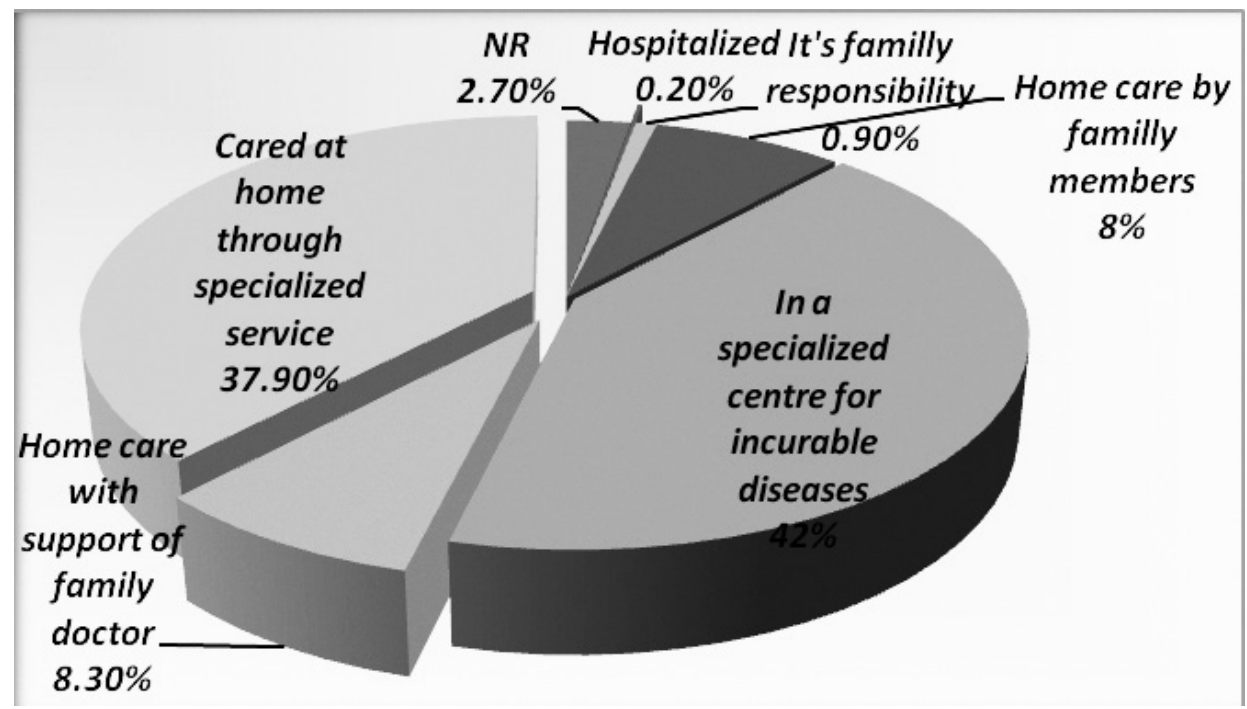

The research revealed that almost 5 million people cared for an incurable person in advanced stage, usually a member of the family or a relative. The survey also determined that the support received from primary care (general practitioners or nurse) is very low; only $11.5 \%$ of family members felt they were assisted in the process of care by their family doctor or nurse.

One of the major symptoms identified by the care givers who care for people with incurable conditions is the high level of pain experienced by the patient, thus $71 \%$ identified the need for access to medication to relieve the

36 National survey conducted by IMAS SA Romania, on Hospice Casa Speranţei request, 2007; 1998 respondents using a probabilistic sample with national representation. 
pain. The following two ranking priorities were qualified support (physician and nurse) for regular visits at home: $54.7 \%$ and qualified support for communication about disease, evolution of condition and patients' fears: $35.1 \%$.

$55 \%$ of the respondents indicated that a major need in caring for a person at home with a life-limiting illness is the need for specialized support from the medical staff (physician and nurse) delivered at the patient's location. The public perception regarding the best solution in helping a patient in advanced stage of an incurable disease is to deliver the care for these beneficiaries at home or in a center with a specialized service. (see above)

\section{Conclusion}

Palliative care has been proved in recent decades as a valuable solution for relieving suffering for persons confronted with cancer and other life limiting diseases. It has a positive impact on the quality of life of the suffering persons and their relatives and on the society at large. It is opposed to euthanasia as it affirms life and the value of the person till his/her end. There is still misunderstanding around the concept even among health care providers and also in the general public. Romania has made some progress in developing the services and in this effort NGO's and especially Hospice Casa Speranţei has played a crucial role. With the current provision just 1 out of 20 patients in need can access a palliative care service in Romania.

Acknowledgement: part of this article is based on the work done with colleagues from UK (Marilyn Boggust, John Smith) and Hospice Casa Speranţei (Malina Dumitrescu, Flavia Hurducas, Nicoleta Mitrea, Andrea Rachitean, Cristina Ghiran, Oana Predoiu) to produce a national palliative care strategy for Romania. Thank you for the contribution. 